\title{
Genome-wide association of echocardiographic dimensions, brachial artery endothelial function and treadmill exercise responses in the Framingham Heart Study
}

\author{
Ramachandran S Vasan*1,2, Martin G Larson1,3, Jayashri Aragam4, \\ Thomas J Wang5, Gary F Mitchell 6 , Sekar Kathiresan ${ }^{5,7}$, Christopher Newton- \\ Cheh $^{5,7}$, Joseph A Vita², Michelle J Keyes ${ }^{1,3}$, Christopher J O'Donnell ${ }^{1,8}$, \\ Daniel Levy ${ }^{1,8}$ and Emelia J Benjamin ${ }^{1,2}$
}

Address: ${ }^{1}$ The National Heart, Lung, and Blood Institute's Framingham Heart Study, Framingham, MA, USA, ${ }^{2}$ Evans Department of Medicine and Whitaker Cardiovascular Institute, Boston University School of Medicine, Boston, MA, USA, ${ }^{3}$ Department of Mathematics and Statistics, Boston University, Boston, MA, USA, ${ }^{4}$ Veterans Administration Hospital, West Roxbury, MA, USA, ${ }^{5}$ Cardiology Division, Massachusetts General Hospital, Harvard Medical School, Boston, MA, USA, ${ }^{6}$ Cardiovascular Engineering, Inc., Waltham, MA, USA, ${ }^{7}$ Program in Medical and Population Genetics, Broad Institute of Massachusetts Institute of Technology and Harvard University, Cambridge, MA, USA and ${ }^{8}$ National Heart, Lung, and Blood Institute, National Institutes of Health, Bethesda, MD, USA

Email: Ramachandran S Vasan* - vasan@bu.edu; Martin G Larson - mlarson@bu.edu; Jayashri Aragam - Jayashri.Aragam@va.gov; Thomas J Wang - tjwang@partners.org; Gary F Mitchell - GaryFMitchell@mindspring.com; Sekar Kathiresan - skathiresan1@partners.org; Christopher Newton-Cheh - cnewtoncheh@partners.org; Joseph A Vita - jvita@bu.edu; Michelle J Keyes - mjkeyes@bu.edu; Christopher J O'Donnell - codonnell@nih.gov; Daniel Levy - levyd@nih.gov; Emelia J Benjamin - emelia@bu.edu

* Corresponding author

Published: 19 September 2007

BMC Medical Genetics 2007, 8(Suppl I):S2 doi:10.1 186/I47I-2350-8-SI-S2

This article is available from: http://www.biomedcentral.com/I47I-2350/8/SI/S2

(C) 2007 Vasan et al; licensee BioMed Central Ltd.

This is an open access article distributed under the terms of the Creative Commons Attribution License (http://creativecommons.org/licenses/by/2.0), which permits unrestricted use, distribution, and reproduction in any medium, provided the original work is properly cited.

\begin{abstract}
Background: Echocardiographic left ventricular (LV) measurements, exercise responses to standardized treadmill test (ETT) and brachial artery (BA) vascular function are heritable traits that are associated with cardiovascular disease risk. We conducted a genome-wide association study (GWAS) in the community-based Framingham Heart Study.

Methods: We estimated multivariable-adjusted residuals for quantitative echocardiography, ETT and BA function traits. Echocardiography residuals were averaged across 4 examinations and included LV mass, diastolic and systolic dimensions, wall thickness, fractional shortening, left atrial and aortic root size. ETT measures (single exam) included systolic blood pressure and heart rate responses during exercise stage 2, and at 3 minutes post-exercise. BA measures (single exam) included vessel diameter, flow-mediated dilation (FMD), and baseline and hyperemic flow responses. Generalized estimating equations (GEE), family-based association tests (FBAT) and variance-components linkage were used to relate multivariable-adjusted trait residuals to 70,987 SNPs (Human I00K GeneChip, Affymetrix) restricted to autosomal SNPs with minor allele frequency $\geq 0.10$, genotype call rate $\geq 0.80$, and Hardy-Weinberg equilibrium $p \geq 0.00 \mathrm{I}$.
\end{abstract}

Results: We summarize results from 17 traits in up to 1238 related middle-aged to elderly men and women. Results of all association and linkage analyses are web-posted at http://ncbi.nlm.nih.gov/projects/gap/cgi-bin/study.cgi?id=phs000007. We confirmed modest-to-strong heritabilities (estimates $0.30-0.52$ ) for several Echo, ETT and BA function traits. Overall, $p<10^{-5}$ in either GEE or FBAT models were observed for 2 I SNPs (nine for echocardiography, eleven for ETT and one for BA function). The top SNPs associated were (GEE results): LV diastolic dimension, rs 1379659 (SLIT2, $\mathrm{P}=$ I. I7*10-7); LV systolic dimension, rs 10504543 (KCNB2, $\left.p=5.18^{*} 10^{-6}\right)$; LV mass, rs 1049809I ( $\left.=5.68^{*} 10^{-6}\right)$; Left atrial size, rs 193588I (FAM5C, $\left.\mathrm{p}=6.56 * 10^{-6}\right)$; exercise heart rate, rs6847I49 (NOLAI, $\left.\mathrm{p}=2.74 * 10^{-6}\right)$; exercise systolic blood 
pressure, rs2553268 (WRN, $\left.\mathrm{p}=6.3^{*} 10^{-6}\right)$; BA baseline flow, rs38I42I9 (OBFCI, 9.48*10-7), and FMD, rs4I48686 (CFTR, $\mathrm{P}=1.13^{*}\left(0^{-5}\right)$. Several SNPs are reasonable biological candidates, with some being related to multiple traits suggesting pleiotropy. The peak LOD score was for LV mass (4.38; chromosome 5); the I.5 LOD support interval included NRG2.

Conclusion: In hypothesis-generating GWAS of echocardiography, ETT and BA vascular function in a moderate-sized community-based sample, we identified several SNPs that are candidates for replication attempts and we provide a webbased GWAS resource for the research community.

\section{Background}

Cardiovascular disease (CVD) is a leading cause of morbidity and mortality in the United States [1]. It is increasingly recognized that CVD is a life-course disease, with overt events being antedated by subclinical cardiovascular target organ damage $[2,3]$. Current research indicates a fundamental role of left ventricular (LV) chamber size, wall thickness (LV remodeling) and mass (LVM) in the pathogenesis of high blood pressure [4,5], and clinical CVD [6,7], including stroke [8,9] and heart failure [1012]. On a parallel note, exercise treadmill stress testing (ETT) is used routinely to evaluate patients with chest pain suggestive of ischemic etiology and for identifying individuals at intermediate pre-test probability of CVD who are more likely to develop clinical events [13]. Likewise, endothelial dysfunction, as assessed via brachial artery (BA) flow-mediated dilation (FMD), has emerged as a fundamental component of atherosclerosis and a precursor of overt CVD [14-16]. Thus, traits obtained via echocardiography (Echo), testing for BA endothelial function and ETT can serve as intermediate phenotypes in the pathway from standard risk factor to overt CVD. Such intermediate phenotypes have been studied extensively to characterize their clinical and genetic correlates, have been reported to be heritable traits [14,17-28], and have been linked to select genetic loci in several reports [2931].

More recently, several investigators have proposed genome-wide association studies (GWAS) as a strategy to map causal genes with modest influences on traits associated with complex diseases such as CVD [32,33]. The availability of $100 \mathrm{~K}$ genotype data on a subset of related Framingham Heart Study participants [34] provides a unique opportunity to conduct both genome-wide association and linkage analyses to explore the genetic underpinnings of LV remodeling, endothelial function and exercise performance in a community-based sample.

\section{Methods}

The design and selection criteria of the Original Framingham Study [35] and the Offspring Study [36] have been described elsewhere. As detailed in the Overview [37], 1345 participants (1087 Offspring and 258 Original Cohort) underwent genotyping using the Affymetrix GeneChip Human Mapping 100K single nucleotide poly- morphism (SNP) set [34]. Participants were eligible for the present investigation if they had available genotypes and the echocardiographic, vascular and ETT traits of interest (as defined below). The Institutional Review Board at Boston University Medical Center approved the study and all participants gave written informed consent (including for genetic research).

\section{Measurement of phenotypes \\ Echocardiography}

All attendees underwent routine transthoracic twodimensionally-guided M-mode echocardiography at the second (1979-1982), fourth (1987-1990), fifth (19911995) and sixth (1996-1998) Offspring cohort examinations. Echocardiographic equipment for image acquisition varied across these examinations: at examination cycle 2, a Hoffrel 201 ultrasound receiver (and Aerotech transducer) was used; at examinations 4 and 5, a Hewlett Packard (model 77020AC) ultrasound machine was used; at examination 6 images were acquired using a Sonos 1000 Hewlett-Packard machine. At all four examinations, however, measurements of LV internal dimension in diastole (LVDD) and systole (LVDS), the thicknesses of the posterior wall (PW) and interventricular septum (IVS), and the diameters of the aortic root (all measured at enddiastole) and left atrium (LA) at end-systole were obtained by using a 'leading edge' technique [38], averaging measurements in 3 cardiac cycles according to the American Society of Echocardiography guidelines. We calculated LV wall thickness (LVWT) as the sum of PW and IVS measurements. LV mass was calculated by using the formula $0.8\left[1.04(\text { LVDD }+ \text { IVS }+ \text { PW })^{3}-(\text { LVDD })^{3}\right]+0.6$ [39]. The reproducibility of Echo measurements was systematically assessed at the sixth examination [40].

\section{ETT measures}

At the second Offspring examination (1978-1981), all attendees underwent submaximal exercise test according to the standard Bruce protocol for up to five incremental 3-minute stages. The test was terminated (without a cool down period) when participants reached their target heart rate ( $85 \%$ age-predicted peak heart rate). Blood pressure measurements and electrocardiograms were recorded during exercise at the midpoint of each 3-minute exercise stage, and for each minute for up to 4 minutes into the recovery period. 


\section{BA endothelial function}

As described previously [14], BA flow-mediated dilation (FMD; percent change in diameter from baseline; i.e. 100 * [hyperemic diameter at 1 minute - baseline diameter]/ baseline diameter) and mean hyperemic flow velocity $(\mathrm{cm} / \mathrm{sec})$ were determined during the seventh clinical examination cycle (1998-2001). A Toshiba SSH-140A ultrasound system with a $7.5 \mathrm{MHz}$ linear array transducer and commercially available software (Brachial Analyzer version 3.2.3, Medical Imaging Applications) were used. Investigators, blinded to participant clinical and genetic data, determined brachial artery diameter at baseline and 1 minute after reactive hyperemia induced by 5 -minute forearm cuff occlusion. The coefficient of variation for baseline and hyperemic diameters were $0.5 \%$ and $0.7 \%$, respectively.

Doppler flow was assessed at baseline and during reactive hyperemia using a $3.75 \mathrm{MHz}$ carrier frequency and with correction for the insonation angle [41]. Mean baseline and hyperemic flow velocities were analyzed from digitized audio data using semiautomated signal averaging (Cardiovascular Engineering, Waltham, MA). Baseline and deflation flow measurements were reproducible on repeated analysis of 30 subjects with correlations of $>0.98$.

\section{Genotyping methods}

The Overview [37] details the genotyping performed with the Affymetrix 100K SNP GeneChip http://gmed.bu.edu/ about/genotyping.html[34] and with the Marshfield STR marker set at the Mammalian Genotyping Service http:// research.marshfieldclinic.org/genetics.

\section{Statistical methods}

We generated normalized sex-specific residuals adjusting for the following covariates: for the echocardiographic phenotypes, age, sex, height, weight, smoking, systolic and diastolic blood pressure, hypertension treatment; for ETT measures, age, sex, body mass index, baseline heart rate, diabetes, smoking, ratio of total to high-density lipoprotein cholesterol, and treatment for hypertension (additional adjustments for select variables is detailed in Table 1); for BA function, a set of 15 covariates previously reported [14] to be associated with endothelial function in our sample (see Table 1). Covariates were from the same exam as the phenotype measures. Next, we used residuals for the phenotypes of interest to test for potential association with $100 \mathrm{~K}$ SNPs using additive familybased association tests (FBAT) and linear regression models with general estimating equations (GEE; additive genetic models) to account for correlation among related individuals from nuclear families, as detailed in the Overview [37]. We chose 70,987 SNPS for association analysis that met the following criteria: autosomal SNPs with genotypic call rate $\geq 80 \%$, minor allele frequency $\geq 10 \%$,
Hardy-Weinberg equilibrium test $\mathrm{p} \geq 0.001$, and $\geq 10$ informative families for FBAT. The choice of an $80 \%$ genotyping call rate threshold may appear unusually liberal. We chose this threshold to be more inclusive in terms of associations reported. Also, the algorithm for the genotype calls was the Dynamic Modeling algorithm, which is less precise than other algorithms that have been introduced more recently. The association analyses were complemented by linkage analyses that used variance components methods and a subset of $100 \mathrm{~K}$ markers and Marshfield STRs; the selection of markers and methods for calculating identity-by-descent are also described in the Overview [37].

We used an unfiltered approach and report the top 25 SNPs associated with echocardiographic traits, ETT measures and BA phenotypes (15, 5 and 5 SNPs, respectively; relative proportions chosen empirically because of the larger number of echocardiographic traits analyzed) according to their degree of statistical significance (lowest $\mathrm{p}$ values) in GEE and FBAT models separately. For echocardiographic phenotypes, we analyzed the mean of values for traits averaged across the 4 examinations, as well as traits at individual examinations separately. In order to evaluate potential pleiotropic effects, we examined SNP associations across related sets of traits and listed the top 25 SNPs with the lowest geometric mean of $\mathrm{p}$ values for all echocardiographic traits (averaged across the four examinations), for all ETT measures and for all BA traits (15, 5 and 5 SNPs, respectively, for the 3 groups). Because we analyzed individual echocardiographic traits at each of the four examinations, we also listed the top SNP associations based on the geometric mean of $p$ values for these individual echocardiographic traits across the four examinations. Thus, we use the term 'pleiotropic effects' to refer to whether there were SNPs that were associated with multiple traits within the 3 subgroups. Additionally, we examined associations of SNPs in or within $200 \mathrm{~Kb}$ of the start or terminus of six selected genes (ACE, AGT, AGTR1, ADRB1, VEGF, NOS3) that have been previously reported to be associated with Echo, ETT and BA function phenotypes [30,42-51]. We view these analyses as exploratory because the coverage of the Affymetrix $100 \mathrm{~K}$ GeneChip for these genes was quite limited.

\section{Results}

Table 1 lists the phenotypes analyzed from the three groups (Echo, ETT and BA endothelial function), the number of traits evaluated within each group, and the covariates included in regression models to create residuals. We observed moderate to high heritability of most of the traits evaluated (Table 1; estimates are multivariableadjusted, for covariates noted above under methods, and listed in table footnote). Heritability estimates were $52 \%$ for aortic root dimension, $36-40 \%$ for LV mass, internal 
Table I: Echocardiographic, exercise testing and brachial artery function traits analyzed in participants with I00K genotype data

\begin{tabular}{lccc}
\hline \multicolumn{1}{c}{ Trait } & Number of Traits* & Offspring Exam cycles & Adjustment ${ }^{\dagger}$ Heritability \\
\hline A. Echocardiographic Traits Averaged Across & 4 Examinations & & \\
\hline LV mass (LVM) & 10 & $2,4,5,6$ & - age- and sex- \\
& & & - multivariable-** \\
LV diastolic dimension (LVDD) & 10 & $2,4,5,6$ & 0.36 \\
LV systolic dimension (LVDS) & 10 & $2,4,5,6$ & 0.38 \\
LV wall thickness (LVWT) & 10 & $2,4,5,6$ & 0.30 \\
LV fractional shortening (LVF) & 10 & $2,4,5,6$ & 0.41 \\
Left atrial diameter (LAD) & 10 & $2,4,5,6$ & 0.20 \\
Aortic root diameter (AOR) & 10 & $2,4,5,6$ & 0.52 \\
\end{tabular}

\section{B. Exercise Treadmill Test (ETT) Traits}

\begin{tabular}{|c|c|c|c|c|}
\hline Stage 2 Exercise systolic blood pressure (SBP) & 2 & 2 & $\begin{array}{l}\text { - age- and sex- } \\
\text { - multivariable-** }\end{array}$ & 0.28 \\
\hline Stage 2 Exercise diastolic blood pressure (DBP) & 2 & 2 & & 0.22 \\
\hline Stage 2 Exercise heart rate & 2 & 2 & & 0.25 \\
\hline Post-exercise 3 minute recovery SBP & 2 & 2 & & 0.20 \\
\hline Post-exercise 3 minute recovery DBP & 2 & 2 & & 0.16 \\
\hline Post-exercise 3 minute recovery heart rate & 2 & 2 & & 0.40 \\
\hline
\end{tabular}

\section{Brachial Artery (BA) Endothelial Function Traits}

\begin{tabular}{llcc}
\hline Baseline BA diameter & 2 & 7 & -25 \\
& & 7 & - multivariable- $* *$ \\
Baseline BA flow velocity & 2 & 7 & 0.32 \\
BA flow-mediated dilation (FMD) percent & 2 & 0.19 & 7 \\
BA hyperemic flow velocity & 2 & 0.06 \\
\hline
\end{tabular}

$\mathrm{BA}=$ brachial artery. $\mathrm{LV}=$ left ventricular. $\mathrm{SBP}=$ systolic blood pressure. $\mathrm{DBP}=$ diastolic blood pressure.

* For Echo traits, the phenotypes listed include those based on averaged values across 4 examinations. Overall, the number of Echo phenotypes includes individual traits at each exam $(\times 2$ for two levels of adjustment in models) plus the averaged traits across 4 exams $(\times 2$ for two levels of adjustment in models) listed above. For ETT and BA traits, the number of individual traits includes traits at single exams ( $\times 2$ for two levels of adjustment in models).

** covariates in multivariable models include:

For Echo phenotypes: age, sex, height, weight, smoking, systolic blood pressure, diastolic blood pressure, hypertension treatment.

For ETT phenotypes: age, sex, BMI, diabetes, current smoking, baseline heart rate, hypertension treatment, total/HDL cholesterol. Additional adjustments were ETT phenotype-specific: Exercise SBP was also adjusted for systolic BP at rest; exercise DBP for diastolic BP at rest; exercise heart rate for heart rate at rest; Recovery SBP for systolic BP at rest, systolic BP during second stage of exercise, and peak systolic BP during exercise; Recovery DBP for diastolic BP at rest, diastolic BP during second stage of exercise, and peak diastolic BP during exercise; and recovery heart rate for heart rate at rest, during second stage of exercise, and peak heart rate during exercise.

For BA phenotypes: age, sex, mean arterial pressure, pulse pressure, heart rate, diabetes, body mass index, fasting blood glucose, prevalent cardiovascular disease, hormone replacement therapy use, walk test before and after BA test, Total/HDL cholesterol, smoking within 6 hrs of BA test, hypertension, lipid-lowering treatment use.

dimensions and LVWT, and 25\% for LA size. Estimates for ETT measures varied from $41 \%$ for post-exercise recovery heart rate, 28\% for exercise systolic blood pressure, and $16-25 \%$ for other phenotypes. For BA function, baseline flow velocity and vessel diameter were most heritable (32 and $25 \%$, respectively) and hyperemic flow the least $(6 \%)$, with intermediate values for FMD (19\%).

Results of all association analyses and detailed linkage results are web-posted at http://ncbi.nlm.nih.gov/ projects/gap/cgi-bin/study.cgi?id=phs000007, the database of genotype and phenotype public repository (dbGaP) at the National Center for Biotechnology Infor- mation. Overall, nine SNPs yielded a p value $<10^{-5}$ in either GEE or FBAT models for Echo traits. Eleven SNPs were associated with ETT traits with a p value $<10^{-5}$, and one SNP yielded a p value below this threshold for BA function traits. A conservative Bonferroni correction for the number of statistical tests $(0.05 / 1,000,000)$ yields an approximate threshold of genome-wide significance of $5^{*} 10^{-8}$.

Table 2A displays the 25 most significantly associated SNPs in GEE analyses (15 for echo phenotypes; 5 each for ETT and BA phenotypes; additive genetic models) sorted by $\mathrm{p}$ values along with the corresponding $\mathrm{p}$ value using 
FBAT. The top SNPs associated with averaged Echo traits included: rs1379659 and rs666088 (both in SLIT2) with LV diastolic dimension, rs1935881 (FAM5C) and rs10493389 (PDE4B) with LA diameter, and rs10504543 (KCNB2) with LV systolic dimension. The top SNPs associated with ETT traits included: rs6847149 (NOLA1) and rs2056387 (RYR2) with stage 2 exercise heart rate, and rs2553268 (WRN) with stage 2 exercise systolic blood pressure. The top $5 \mathrm{SNPs}$ associated with BA traits included rs3814219 (OBFC1) and rs10515508 (NRG2) with BA baseline flow, and rs4148686 (CFTR) with FMD. Only one of these SNPs (SLIT2) had a p value $<10^{-3}$ in FBAT.

Table 2B lists the top 25 SNPs associated with phenotypes in FBAT along with corresponding $\mathrm{p}$ values in GEE models. Only one of these SNPs (rs1959290 associated with LV systolic dimension) had a p value $<10^{-3}$ in GEE models. The top 5 SNPs associated with ETT traits included rs1029947 and rs1029946 (both in PRKAG2) with heart rate at 3 minutes of post-exercise recovery. The top 5 SNPs associated with BA traits included rs2389866 (PDE5A).

Table 2C lists the magnitude and the location of loci with LOD scores that exceeded 2.0. The peak LOD scores were: for Echo traits, 4.38 (chromosome 5) for LV mass and 4.23 (chromosome 3) for aortic root size; for ETT traits, 2.93 (chromosome 5), 2.46 (chromosome 1), and 2.43 (chromosome 22) for heart rate during stage 2 of exercise; for BA traits, 2.14 (chromosome 8) for baseline flow velocity.

Table 3 evaluates the potential pleiotropic effect of SNPs by evaluating the geometric mean of $\mathrm{p}$ values for associations across averaged echo, and single-exam ETT and BA traits, and by relating them to the individual Echo traits across 4 examinations. SNPs associated with 4 genes (SLIT2, WDR72, UBE2L3 and KCNB2) were related to individual echo traits across examinations, as well as associated with the averaged Echo traits. Likewise, RYR2 was associated with a low geometric $\mathrm{p}$ value when related to all ETT traits across the examination.

Table 4A-C displays results of association of Echo, ETT and BA function traits with SNPs in proximity to 6 genes (within $200 \mathrm{~Kb}$ of the start or terminus) chosen from the published literature; as noted earlier, the Affymetrix $100 \mathrm{~K}$ GeneChip does not cover SNPs within these genes adequately. We observed weak associations of several SNPs in proximity to the genes of interest and Echo, ETT and BA function traits, none of which had a p value $<10^{-3}$ ). It is noteworthy, though, that several SNPs in proximity to ADRB1, AGT, and AGTR1 were associated weakly (p value of 0.05 to $10^{-3}$ ) with several Echo, ETT and BA function phenotypes.

\section{Discussion \\ Principal findings}

We report results of GWAS of Echo, ETT and BA function traits in a moderate-size community-based sample using several complementary analytical approaches. Our principal findings are five-fold. First, we observed modest to strong evidence of heritability for several Echo, ETT and BA function traits, underscoring the contribution of additive genetic effects to interindividual variation in these traits. Our heritability findings confirm prior reports for some of the traits $[18,20,22,23,27,28,52]$, including from our group $[14,24]$. Second, notwithstanding the modestto-high heritability, none of the SNP-trait associations we observed achieved genome-wide significance (conservative Bonferroni correction $\mathrm{p}$ of $\left.5^{*} 10^{-8}\right)$. Therefore, any associations presented should be viewed as hypothesisgenerating, with need for replication in additional samples. Third, our investigation highlights some of the challenges inherent in the interpretation of GWAS results. We did not observe any overlap between the top SNPs noted in GEE-based versus FBAT-based analyses, in part due to the inherent differences in the two analytical methods (see Overview for details [37]). Fourth, notwithstanding the lack of genome-wide statistical significance, our data do suggest several interesting biological candidates among the SNPs most strongly associated with different traits in the various analytical approaches (see discussion below). Fifth, we were quite limited in our ability to replicate findings for genetic variants previously associated with the traits that we investigated because specific coverage of such genetic variation in these candidates was limited in the Affymetrix 100K GeneChip. Therefore, the lack of replication of SNPs in proximity to 6 genes previously reported to be associated with Echo, ETT and BA traits should be interpreted with great caution. It is interesting that several weak associations ( $\mathrm{p}$ between 0.05 and $10^{-3}$ ) were observed between traits in the three groups and SNPs in proximity to selected candidate genes evaluated (ADRB1, AGT and AGTR1).

\section{Potential biological candidates among observed associations}

In our GWAS of Echo traits, a SNP in SLIT2 was associated with Echo LV diastolic dimension in several analyses. SLIT2 is an evolutionarily highly conserved gene that encodes a putative secreted protein, which contains conserved protein-protein interaction domains including leucine-rich repeats and epidermal growth factor-like motifs [53]. The gene has multiple effects but has been recently identified to have a novel role in vascular function by contributing to migratory mechanisms in vascular smooth muscle cells [54]. Likewise, the associations of LV mass with HSPA8, and of LA size with PDE4B are consistent with the key role of heat shock protein expression [55] and T-cell mediated immune responses [56], respectively, 
Table 2: Top associations for Echo, ETT and BA function traits based on lowest p value for GEE test (2a), FBAT (2b), and Linkage (2c)*

\section{A. Top Associations based on lowest GEE $p$ values}

\begin{tabular}{lllll}
\hline Trait & SNP $\quad$ Chromosome Physical position GEE p-value FBAT p-value In/near Gene (within 60 kb)
\end{tabular}

I. Top I5 SNPs associated with Echocardiographic Traits (Averaged across exams)

\begin{tabular}{|c|c|c|c|c|c|c|}
\hline LV diastolic dimension & rs 1379659 & 4 & 20296952 & $1.17 * 10^{-7}$ & 0.001 & SLIT2 \\
\hline LV fractional shortening & rs366676 & 6 & 88774485 & $2.44 * 10^{-6}$ & 0.059 & SPACAI \\
\hline LV diastolic dimension & rs666088 & 4 & 20171404 & $5.10 * 10^{-6}$ & 0.008 & SLIT2 \\
\hline LV systolic dimension & rs 10504543 & 8 & 73941196 & $5.18 * 10^{-6}$ & 0.247 & KCNB2 \\
\hline Left atrial diameter & rs193588I & 1 & 186798043 & $5.56 * 10^{-6}$ & 0.003 & FAM5C \\
\hline LV mass & rsl049809I & 2 & 221724949 & $5.68 * 10^{-6}$ & 0.162 & \\
\hline Left atrial diameter & rs10493389 & 1 & 66022886 & $6.56 * 10^{-6}$ & 0.119 & PDE4B \\
\hline LV diastolic dimension & rs4920799 & 5 & 84642284 & $6.84 * 10^{-6}$ & $0.04 I$ & \\
\hline LV wall thickness & rs10519181 & 15 & 76076030 & $1.04 * 10^{-5}$ & 0.027 & $T B C I D 2 B$ \\
\hline LV diastolic dimension & rs6104740 & 20 & 11284809 & $1.15 * 10^{-5}$ & 0.021 & \\
\hline LV diastolic dimension & rs2900208 & 12 & || $76973 \mid$ & $1.20 * 10^{-5}$ & 0.021 & ETV6 \\
\hline LV systolic dimension & rs3766377 & 1 & 157613632 & $1.25 * 10^{-5}$ & 0.032 & $C D 244$ \\
\hline LV diastolic dimension & rs105II762 & 9 & 25621130 & $1.29 * 10^{-5}$ & 0.002 & TUSCI \\
\hline LV mass & rs4936770 & 11 & 122434085 & $1.37 * 10^{-5}$ & 0.019 & HSPA8 \\
\hline LV diastolic dimension & rs4485619 & 20 & 11251676 & $1.57 * 10^{-5}$ & 0.043 & \\
\hline
\end{tabular}

II. Top 5 SNPs associated with ETT Traits

\begin{tabular}{|c|c|c|c|c|c|c|}
\hline Stage 2 Exercise heart rate & rs6847I49 & 4 & 111157701 & $2.74 * 10^{-6}$ & 0.014 & NOLAI \\
\hline Stage 2 Exercise heart rate & rs2819770 & 1 & 234237045 & $3.53 * 10^{-6}$ & 0.010 & RYR2 \\
\hline Post-exercise 3 minute recovery SBP & rs746463 & 11 & 109501154 & $4.88 * 10^{-6}$ & 0.564 & \\
\hline Stage 2 Exercise heart rate & rs2056387 & 1 & 234250153 & $5.17 * 10^{-6}$ & 0.002 & RYR2 \\
\hline Stage 2 Exercise SBP & rs2553268 & 8 & 31055898 & $6.32 * 10^{-6}$ & 0.001 & WRN \\
\hline
\end{tabular}

III. Top 5 SNPs associated with BA endothelial function Traits

\begin{tabular}{|c|c|c|c|c|c|c|}
\hline Baseline BA flow velocity & rs3814219 & 10 & 105637085 & $9.48 * 10^{-7}$ & 0.325 & OBFCI \\
\hline BA FMD percent & rs4l48686 & 7 & 116728468 & $1.13 * 10^{-5}$ & 0.025 & CFTR \\
\hline Baseline BA flow velocity & rs1471639 & 14 & 33552277 & $1.26 * 10^{-5}$ & 0.001 & \\
\hline Baseline BA diameter & rs1045I82 & 6 & 116705168 & $1.44 * 10^{-5}$ & 0.058 & TSPYLI \\
\hline Baseline BA flow velocity & rs 10515508 & 5 & 139355254 & $1.71 * 10^{-5}$ & 0.016 & $N R G 2$ \\
\hline
\end{tabular}

2B. Top associations based on lowest FBAT p value

$$
\text { Trait SNP Chromosome Physical position GEE p-value FBAT p-value In/near Gene (within } 60 \text { kb) }
$$

I. Top I5 SNPs associated with Echocardiographic Traits (Averaged across exams)

\begin{tabular}{|c|c|c|c|c|c|c|}
\hline LV systolic dimension & rs I392284 & 3 & 114584100 & 0.139 & $6.39 * 10^{-6}$ & WDR52 \\
\hline LV fractional shortening & rs 10515040 & 17 & 48859319 & 0.211 & $1.29 * 10-5$ & \\
\hline LV fractional shortening & rs9312006 & 3 & 8234491 & 0.002 & $1.64 * 10^{-5}$ & \\
\hline LV systolic dimension & rs1050459| & 8 & 76199715 & 0.046 & $1.95 * 10-5$ & \\
\hline LV fractional shortening & rs448458 & 15 & 60591780 & 0.206 & $2.26 * 10^{-5}$ & \\
\hline LV diastolic dimension & rs580859 & 13 & 68030441 & 0.046 & $2.68 * 10^{-5}$ & \\
\hline LV systolic dimension & rs 1959290 & 14 & 86208482 & $2.07 * 10^{-5}$ & $6.42 * 10^{-5}$ & \\
\hline Aortic root diameter & rs2468680 & 8 & 140590402 & 0.690 & $6.12 * 10^{-5}$ & \\
\hline LV systolic dimension & rs448458 & 15 & 60591780 & 0.019 & $5.60 * 10^{-5}$ & \\
\hline LV systolic dimension & rs2918268 & 5 & 148586949 & 0.574 & $4.82 * 10^{-5}$ & ABLIM3 \\
\hline LV mass & rs965036 & 6 & 20099022 & 0.033 & $3.69 * 10^{-5}$ & \\
\hline Left atrial diameter & rsI70182I & 7 & 112544622 & 0.137 & $3.66 * 10^{-5}$ & \\
\hline
\end{tabular}


Table 2: Top associations for Echo, ETT and BA function traits based on lowest p value for GEE test (2a), FBAT (2b), and Linkage (2c)* (Continued)

\begin{tabular}{lllrrr}
\hline Aortic root diameter & rs7544568 & I & 38308301 & 0.194 & $3.21 * 10^{-5}$ \\
LV fractional shortening & $r s 10504591$ & 8 & 76199715 & 0.112 & $2.92 * 10^{-5}$ \\
LV diastolic dimension & rsl488745 & 3 & 1976802 & 0.141 & $\mathbf{2 . 7 2 * 1 0 - 5}$
\end{tabular}

\section{Top 5 SNPs associated with ETT Traits}

\begin{tabular}{|c|c|c|c|c|c|c|}
\hline Post-exercise 3 minute recovery SBP & rs2016718 & 8 & 96813381 & 0.006 & $2.20 * 10^{-7}$ & \\
\hline $\begin{array}{l}\text { Post-exercise } 3 \text { minute recovery heart } \\
\text { rate }\end{array}$ & rsI029947 & 7 & $1507 \mid 3400$ & 0.013 & $9.20 * 10^{-7}$ & PRKAG2 \\
\hline $\begin{array}{l}\text { Post-exercise } 3 \text { minute recovery heart } \\
\text { rate }\end{array}$ & rsl029946 & 7 & $1507 \mid 3454$ & 0.022 & $3.89 * 10^{-6}$ & PRKAG2 \\
\hline Stage 2 Exercise heart rate & rsl958055 & 14 & 33254537 & 0.040 & $8.55 * 10^{-6}$ & NPAS3 \\
\hline Post-exercise 3 minute recovery SBP & rs7828552 & 8 & 71862761 & 0.057 & $9.34 * 10^{-6}$ & $X R G 9$ \\
\hline
\end{tabular}

III. Top 5 SNPs associated with BA endothelial function Traits

\begin{tabular}{|c|c|c|c|c|c|c|}
\hline BA hyperemic flow velocity & rs 1859634 & 7 & 100758808 & 0.030 & $1.21 * 10^{-5}$ & $A K I 24 I 20$ \\
\hline BA FMD percent & rsII06494 & 14 & 62201734 & 0.003 & $1.61 * 10^{-5}$ & KCNH5 \\
\hline BA hyperemic flow velocity & rs2389866 & 4 & 120872866 & 0.423 & $2.12 * 10^{-5}$ & PDE5A \\
\hline Baseline BA diameter & rs774227 & 9 & 91273496 & 0.002 & $2.34 * 10^{-5}$ & NFIL3 \\
\hline Baseline BA diameter & rsI0502887 & 18 & 43433881 & 0.002 & $2.79 * 10-5$ & \\
\hline
\end{tabular}

2C. Magnitude and location of peak LOD scores $\geq 2.0$ for Echo, ETT and BA function traits

\begin{tabular}{llllll}
\hline Trait & SNP or & Chromosome Physical position $\begin{array}{c}\text { Maximum } \\
\text { STR score }\end{array}$ & LOD-I.5 \\
interval & & LOD+I.5 interval
\end{tabular}

\section{Echocardiographic Traits (Averaged across examinations)}

\begin{tabular}{|c|c|c|c|c|c|c|}
\hline LV mass & rs10515509 & 5 & 139270238 & 4.37 & 133816612 & 150634674 \\
\hline Aortic root diameter & rs 10513442 & 3 & I54474088 & 4.22 & 150552924 & 161813142 \\
\hline LV wall thickness & rs3813713 & 10 & 51241137 & 3.16 & 32818116 & 58684005 \\
\hline LV wall thickness & rsI05II550 & 9 & 10638555 & 3.11 & 10220368 & 15384347 \\
\hline LV fractional shortening & AFM254vel & 3 & 198506417 & 2.78 & 195278503 & 199138789 \\
\hline LV wall thickness & rs2438085 & 2 & 105339005 & 2.59 & 103478258 & 106924695 \\
\hline Left atrial diameter & rs73275I4 & 13 & 78334100 & 2.55 & 68655834 & 90511230 \\
\hline LV wall thickness & rs 1719 & 15 & 83149176 & 2.45 & 64238853 & 86738287 \\
\hline LV mass & rs10489725 & 1 & 181172198 & 2.41 & 176249023 & 201595809 \\
\hline LV mass & rs198905I & 8 & 129363300 & 2.38 & $1278 \mid 1630$ & 133926399 \\
\hline LV wall thickness & $\begin{array}{l}\text { GATAI64B } \\
08\end{array}$ & 3 & 8560016 & 2.25 & 2183832 & 20875136 \\
\hline
\end{tabular}

\section{ETT Traits}

\begin{tabular}{llllrrr}
\hline Stage 2 Exercise heart rate & rs 190982 & 5 & 88259176 & 2.93 & 71236666 & 96112374 \\
Stage 2 Exercise heart rate & GATA165C & I & 60383884 & 2.46 & 43070922 \\
Stage 2 Exercise heart rate & rs7286558 & 22 & 20504737 & 2.43 & 15786453 \\
Stage 2 Exercise heart rate & rs 10483844 & 14 & 71902088 & 2.39 & 53240301
\end{tabular}

III. BA Endothelial Function Traits

\begin{tabular}{|c|c|c|c|c|c|c|}
\hline Baseline BA flow velocity & rs|425727 & 8 & 25642697 & 2.14 & 19459783 & 32261074 \\
\hline BA FMD percent & D2ISII & 21 & 19476134 & 2.13 & 10000969 & 27037800 \\
\hline Baseline BA flow velocity & rs3007456 & 9 & 42925816 & 2.12 & 36878975 & 76736108 \\
\hline
\end{tabular}

*SNPs are ordered by GEE p values. dbSNP positions are from NCBI Build 35 (hgl7).

Abbreviations as in Table I. The number of informative families for FBAT analyses ranged from a minimum of 80 to a maximum of 210 . 
Table 3: Top associations ordered by geometric mean of GEE p-values across traits (3 groups) and across examinations (echo traits)

\begin{tabular}{|c|c|c|c|c|c|}
\hline Trait & SNP & Chromosome & Physical position & GEE p-value & In/near Gene (within 60 kb) \\
\hline \multicolumn{6}{|c|}{ IA. Top I5 SNPs associated with Echocardiographic Traits across individual exams } \\
\hline LV diastolic dimension & rs4920799 & 5 & 84642284 & 0.001 & \\
\hline LV diastolic dimension & rs 1379659 & 4 & 20296952 & 0.001 & SLIT2 \\
\hline Aortic root diameter & rs26438 & 5 & 165221499 & 0.001 & \\
\hline LV mass & rs473664 & 15 & 51598287 & 0.0016 & WDR72 \\
\hline Aortic root diameter & rs10488825 & 11 & 81688520 & 0.0017 & \\
\hline LV mass & rsl049809| & 2 & 221724949 & 0.0017 & \\
\hline LV diastolic dimension & rsl05|443| & 16 & 76498035 & 0.0018 & KIAAI576 \\
\hline LV diastolic dimension & rs10505599 & 8 & 133812159 & 0.0019 & FLJ33069 \\
\hline LV systolic dimension & rs10504543 & 8 & 73941196 & 0.0019 & KCNB2 \\
\hline LV diastolic dimension & rs2900208 & 12 & || $76973 \mid$ & 0.0019 & ETV6 \\
\hline LV mass & rs861857 & 22 & 20306894 & 0.0022 & UBE2L3 \\
\hline LV systolic dimension & rs 10501940 & 11 & 99440078 & 0.0023 & CNTN5 \\
\hline LV systolic dimension & rs707025 & 2 & $|550| 403 \mid$ & 0.0023 & GALNTI3 \\
\hline Aortic root diameter & rs1395204 & 18 & 4477509 & 0.0025 & \\
\hline LV diastolic dimension & rs 10513272 & 9 & 116143601 & 0.0026 & PAPPA \\
\hline
\end{tabular}

IB. Top I5 SNPs associated with Averaged Echocardiographic Traits (across LV traits)

\begin{tabular}{|c|c|c|c|c|c|}
\hline \multirow{15}{*}{ Across LV phenotypes } & rs|379659 & 4 & 20296952 & 0.0007 & SLIT2 \\
\hline & rs1049809| & 2 & 221724949 & 0.0009 & \\
\hline & rs861857 & 22 & 20306894 & 0.001 & UBE2L3 \\
\hline & rs473664 & 15 & 51598287 & 0.0012 & WDR72 \\
\hline & rs3766377 & 1 & $1576 \mid 3632$ & 0.0016 & $C D 244$ \\
\hline & rs 10504543 & 8 & 73941196 & 0.0017 & KCNB2 \\
\hline & rs 10518462 & 4 & $|2656252|$ & 0.0018 & \\
\hline & rs1959289 & 14 & 86208319 & 0.0026 & \\
\hline & rs667269 & 3 & 175822307 & 0.0027 & \\
\hline & rs 1959290 & 14 & 86208482 & 0.0027 & \\
\hline & rs1959291 & 14 & 86208525 & 0.0027 & \\
\hline & rs 10485104 & 6 & $16596635 \mid$ & 0.0030 & PDEIOA \\
\hline & rs10491574 & 9 & 116701992 & 0.0030 & ASTN2 \\
\hline & rs707025 & 2 & $|550| 403 \mid$ & 0.0032 & GALNTI3 \\
\hline & rs525960 & 1 & 149310939 & 0.0033 & LCE5A \\
\hline \multicolumn{6}{|c|}{ II. Top 5 SNPs associated with ETT Traits (across traits) } \\
\hline \multirow[t]{5}{*}{ Across phenotypes } & rsI560916 & 17 & 28973892 & 0.0101 & ACCNI \\
\hline & rs|432214 & 2 & $1377 \mid 2255$ & 0.0106 & \\
\hline & rs 10512056 & 9 & 76835140 & 0.0112 & LOC442425 \\
\hline & rs2056387 & 1 & 234250153 & 0.0115 & RYR2 \\
\hline & rs65608I2 & 10 & 2363105 & 0.0132 & \\
\hline
\end{tabular}

III. Top 5 SNPs associated with BA endothelial Traits (across traits)

\begin{tabular}{lllll}
\hline Across phenotypes & rs2912991 & 7 & 52684247 & 0.0029 \\
& rsl0510677 & 3 & 36168070 & 0.007 \\
& rsl0493052 & 1 & 33614778 & 0.007 \\
& rs715594I & 14 & 41681710 & 0.008 \\
& rsl954627 & 14 & 41689011 & 0.009
\end{tabular}

dbSNP positions are from NCBI Build 35 (hgl7).

Abbreviations as in Table I. 
Table 4: Associations of traits with SNPs in or near (up to $200 \mathrm{~kb}$ away) 6 well-replicated genes in the published literature with a pvalue $<0.05$ in either FBAT or GEE.

4A. Associations of averaged echo traits

\begin{tabular}{|c|c|c|c|c|c|}
\hline Candidate Gene & FHS IOOK SNP & Physical Position & Trait & GEE p-value & FBAT p-value \\
\hline$A C E$ & \multicolumn{5}{|c|}{ no SNP was associated with a $p$ value $<0.05$ for any LV trait studies } \\
\hline \multirow[t]{22}{*}{ ADRBI } & rs10510001 & 115962372 & LV diastolic dimension & 0.004 & 0.0002 \\
\hline & rsl051000I & 115962372 & LV systolic dimension & 0.001 & 0.001 \\
\hline & rs 10510000 & 115961985 & LV diastolic dimension & 0.052 & 0.001 \\
\hline & rs 10510000 & 115961985 & LV systolic dimension & 0.059 & 0.001 \\
\hline & rs7902873 & 115884949 & LV diastolic dimension & 0.467 & 0.002 \\
\hline & rs10509999 & 115917269 & LV diastolic dimension & 0.136 & 0.003 \\
\hline & rs 180940 & $1157|240|$ & LV wall thickness & 0.003 & 0.072 \\
\hline & rs180934 & 115720720 & LV wall thickness & 0.005 & 0.090 \\
\hline & rs 180935 & 115720249 & LV wall thickness & 0.005 & 0.160 \\
\hline & rs998334 & 115957002 & LV diastolic dimension & 0.289 & 0.005 \\
\hline & rs7902873 & 115884949 & LV systolic dimension & 0.249 & 0.006 \\
\hline & rs10509999 & 115917269 & LV systolic dimension & 0.036 & 0.008 \\
\hline & rsl80935 & 115720249 & LV mass & 0.011 & 0.409 \\
\hline & rsl80934 & 115720720 & LV mass & 0.015 & 0.411 \\
\hline & rs7902873 & 115884949 & LV mass & 0.646 & 0.016 \\
\hline & rs998334 & 115957002 & LV systolic dimension & 0.110 & 0.018 \\
\hline & rsl051000I & 115962372 & LV fractional shortening & 0.021 & 0.056 \\
\hline & rs10510000 & 115961985 & LV fractional shortening & 0.382 & 0.027 \\
\hline & rs 180940 & $1157|240|$ & LV mass & 0.029 & 0.303 \\
\hline & rsl051000I & 115962372 & LV mass & 0.393 & 0.040 \\
\hline & rs6585258 & 115739125 & LV mass & 0.047 & 0.481 \\
\hline & rs 10510000 & 115961985 & LV mass & 0.335 & 0.048 \\
\hline \multirow[t]{9}{*}{$A G T$} & rs10495300 & 227188497 & Left atrial diameter & 0.095 & 0.001 \\
\hline & rs2478518 & 227174605 & LV fractional shortening & 0.028 & 0.238 \\
\hline & rsI202585 & 227309949 & LV wall thickness & 0.030 & 0.028 \\
\hline & rs2180478 & 227295655 & LV diastolic dimension & 0.800 & 0.030 \\
\hline & rs758216 & 227005969 & Aortic root diameter & 0.031 & $0.34 I$ \\
\hline & rsI202524 & 227257907 & LV diastolic dimension & 0.323 & 0.037 \\
\hline & rs2478518 & 227174605 & LV systolic dimension & 0.038 & 0.467 \\
\hline & rs731824 & 227329806 & Left atrial diameter & 0.043 & 0.399 \\
\hline & rsI202585 & 227309949 & LV mass & 0.044 & 0.117 \\
\hline \multirow[t]{6}{*}{ AGTRI } & rs 1059502 & 150045008 & Aortic root diameter & 0.598 & 0.005 \\
\hline & rsI357424 & 149801524 & LV fractional shortening & 0.075 & 0.006 \\
\hline & rs1357424 & $14980 \mid 524$ & LV systolic dimension & 0.241 & 0.030 \\
\hline & rs 1059502 & 150045008 & LV diastolic dimension & 0.142 & 0.030 \\
\hline & rs233|406 & 150048180 & Aortic root diameter & 0.589 & 0.032 \\
\hline & rs10513333 & 149786557 & Left atrial diameter & 0.437 & 0.039 \\
\hline \multirow[t]{6}{*}{ VEGF } & rs72976I & 43912549 & LV fractional shortening & 0.012 & 0.200 \\
\hline & rs72976I & 43912549 & Left atrial diameter & 0.573 & 0.018 \\
\hline & rs72976I & 43912549 & LV systolic dimension & 0.018 & 0.249 \\
\hline & rs2396083 & 43912786 & LV fractional shortening & 0.026 & 0.250 \\
\hline & rs2396083 & 43912786 & Left atrial diameter & 0.489 & 0.031 \\
\hline & rs2396083 & 43912786 & LV systolic dimension & 0.040 & 0.224 \\
\hline
\end{tabular}


Table 4: Associations of traits with SNPs in or near (up to $200 \mathrm{~kb}$ away) 6 well-replicated genes in the published literature with a pvalue $<0.05$ in either FBAT or GEE. (Continued)

\begin{tabular}{|c|c|c|c|c|c|}
\hline \multicolumn{6}{|c|}{ 4B. Associations of ETT traits } \\
\hline Candidate Gene & FHS IOOK SNP & Physical Position & Trait & GEE p-value & FBAT p-value \\
\hline \multirow[t]{3}{*}{$A C E$} & rs10491167 & 58780430 & Stage 2 Exercise systolic blood pressure & 0.046 & 0.137 \\
\hline & rs 10491168 & 58795195 & Stage 2 Exercise systolic blood pressure & 0.030 & 0.124 \\
\hline & rs721575 & 59136652 & Post-exercise 3 minute recovery heart rate & 0.024 & 0.025 \\
\hline \multirow[t]{2}{*}{ ADRBI } & rs2419857 & 115607366 & Stage 2 Exercise heart rate & 0.852 & 0.030 \\
\hline & rs4345919 & 115651155 & Post-exercise 3 minute recovery heart rate & 0.048 & 0.740 \\
\hline \multirow[t]{4}{*}{$A G T$} & rs1752189 & 227000046 & Post-exercise 3 minute recovery SBP & 0.145 & 0.021 \\
\hline & rs758216 & 227005969 & Post-exercise 3 minute recovery SBP & 0.184 & 0.050 \\
\hline & rs 10495298 & 227120049 & Stage 2 Exercise systolic blood pressure & 0.288 & 0.050 \\
\hline & rs2478516 & 227175387 & Stage 2 Exercise systolic blood pressure & 0.021 & 0.486 \\
\hline \multirow[t]{3}{*}{ AGTRI } & rs275678 & 149851039 & Post-exercise 3 minute recovery SBP & 0.216 & 0.049 \\
\hline & rs427832 & |4994906| & Post-exercise 3 minute recovery SBP & 0.014 & 0.171 \\
\hline & rs 1949350 & 150089423 & Stage 2 Exercise heart rate & 0.010 & 0.335 \\
\hline VEGF & rs72976I & 43912549 & Stage 2 Exercise heart rate & 0.041 & 0.035 \\
\hline NOS3 & rs2303928 & $150 \mid 76978$ & Stage 2 Exercise heart rate & 0.012 & 0.056 \\
\hline \multicolumn{6}{|c|}{ 4C. Associations of BA function traits } \\
\hline Candidate Gene & FHS IOOK SNP & Physical Position & Trait & GEE p-value & FBAT p-value \\
\hline$A C E$ & & & no SNP was associated with a $\mathrm{p}$ value $<0.05$ & & \\
\hline \multirow[t]{6}{*}{$A D R B I$} & rs 180940 & $1157|240|$ & BA hyperemic flow velocity & 0.581 & 0.015 \\
\hline & rs 180935 & 115720249 & BA hyperemic flow velocity & 0.953 & 0.030 \\
\hline & rs 180934 & II5720720 & BA hyperemic flow velocity & 0.662 & 0.029 \\
\hline & rs10509999 & 115917269 & BA hyperemic flow velocity & 0.001 & 0.137 \\
\hline & rs 10510000 & 115961985 & BA hyperemic flow velocity & 0.007 & 0.014 \\
\hline & rs10510001 & 115962372 & BA hyperemic flow velocity & 0.017 & 0.239 \\
\hline \multirow[t]{3}{*}{$A G T$} & rs758216 & 227005969 & Baseline BA flow velocity & 0.049 & 0.488 \\
\hline & rs 1202585 & 227309949 & Baseline BA diameter & 0.002 & 0.080 \\
\hline & rs 1202585 & 227309949 & BA hyperemic flow velocity & 0.049 & 0.080 \\
\hline \multirow[t]{2}{*}{ AGTRI } & rs 1492090 & |4988475| & BA hyperemic flow velocity & 0.026 & 0.293 \\
\hline & rs427832 & $|4994906|$ & Baseline BA flow velocity & 0.509 & 0.043 \\
\hline \multirow[t]{2}{*}{ VEGF } & rs833048 & 43762514 & BA hyperemic flow velocity & 0.860 & 0.036 \\
\hline & rs 10498756 & 44046909 & BA hyperemic flow velocity & 0.312 & 0.008 \\
\hline \multirow[t]{3}{*}{ NOS3 } & rs741067 & 149938103 & Baseline BA diameter & 0.043 & 0.024 \\
\hline & rs 1006581 & |4994957| & Baseline BA diameter & 0.009 & 0.097 \\
\hline & rs2215564 & 150001612 & BA hyperemic flow velocity & 0.028 & 0.104 \\
\hline
\end{tabular}

dbSNP positions are from NCBI Build 35 (hg l7). 
in myocardial hypertrophic responses to insults or hemodynamic overload.

Analyses of ETT traits provided some interesting results. The association of a SNP in RYR2 with exercise heart rate responses in multiple analyses is quite consistent with the fundamental role of the ryanodine receptor on the sarcoplasmic reticulum in calcium trafficking during cardiac muscle excitation-contraction coupling [57]. Furthermore, RYR2 has been implicated in exercise-induced polymorphic ventricular tachyarrhythmias [58]. Using FBAT, SNPs in PRKAG2 were associated with heart rate during the recovery period post-exercise. Mutations in PRKAG2, an enzyme that modulates glucose uptake and glycolysis [59], are associated with glycogen-filled vacuoles in cardiomyocytes. The phenotypic manifestations include cardiac hypertrophy, ventricular pre-excitation and conduction system disturbances, encompassed together in the Wolff-Parkinson-White syndrome [60].

Genetic linkage analyses of ETT traits identified peaks on chromosomes 5 and 22 for exercise heart rate. The 1.5 LOD support intervals for these peaks included MEF2C and MAPK1, respectively. MEF2C is a critical regulator of cardiac morphogenesis [61]. Additionally, overexpression of MEF2C in experimental studies is associated with disturbances in extracellular matrix remodeling, ion handling, and metabolism of cardiomyocytes [62]. The peak on MAPK1 is of interest because a recent investigations highlighted the role of MAPK signaling in mediating the responses of skeletal muscles to exercise training [63].

A SNP in NRG2 was associated with BA flow velocity at rest, and also was in proximity to the top LOD peak for LV mass, raising the possibility of pleiotropic effects of this gene on ventricular and vascular remodeling and function. NRG2, which encodes neuregulin-2, is a member of the epidermal growth factor (EGF) family and binds to ErbB receptors. ErbB signaling has been implicated in angiogenesis and endothelial cell proliferation [64]. Of interest, a SNP in CFTR was associated with FMD. It is noteworthy that CFTR is expressed in vascular smooth muscle cells and activation of CFTR chloride channels regulates contraction and relaxation of smooth muscle cells; disruption of the CFTR gene prevents cAMP-dependent vasorelaxation in experimental studies [65]. CFTR is also expressed in endothelial cells where it functions as a cyclic nucleotide-regulated chloride channel [66]. Of interest, a SNP in PDE5A was associated with BA hyperemic flow velocity in FBAT analyses. Phosphodiesterase 5 (PDE5) hydrolyzes cyclic guanosine monophosphate (cGMP) and cyclic adenosine monophosphate (CAMP), is widely expressed in the vasculature, and is best known as the target of sildenafil, a drug used to treat erectile dysfunction [67]. PDE5 degrades CGMP in smooth muscle cells so as to maintain the contracted state of blood vessels [67]. PDE5A may also play a critical role in the growth promoting effects of Angiotensin II on vascular smooth muscle cells [68].

\section{Strengths and limitations}

The moderate-sized community-based sample, availability of longitudinal Echo measurements, routine ascertainment of standardized and reproducibly-measured traits, and evaluation of multiple complementary analytical methods including assessment of potential pleiotropic genetic effects strengthen our investigation. By web-posting unfiltered aggregate data we provide a resource for the scientific community to conduct in silico replication. Nonetheless, several limitations must be emphasized. As noted previously, the lack of genome-wide significance for any association observed given the extent of multiple statistical testing does not exclude a potential role of genetic influences on the traits studied. We had limited statistical power to detect modest genetic effects, given the sample size and the extent of multiple testing. As detailed in the Overview paper [37], for a conservative alpha level such as $10^{-8}$, we have more than $90 \%$ power to detect an association with a SNP explaining $4 \%$ or more total phenotypic variation when $80 \%$ or more individuals are phenotyped. We also had limited ability to replicate previously reported findings, in view of the partial coverage of genetic variation in select candidates with the Affymetrix $100 \mathrm{~K}$ gene chip. Additionally, genetic variants may influence phenotypes in a context-specific manner [69], being modulated by environmental influences. For instance, the associations of ACE and AGTR2 with LV mass were reported to vary according to dietary salt intake in one investigation [48]. We did not undertake an investigation of gene-environmental interactions in the present study. Likewise, some of the moderately strong associations may represent false-positive results, notwithstanding the evidence suggesting that some of the associated SNPs may be reasonable biological candidates. We averaged echocardiographic traits across multiple examinations, with a view to characterizing the phenotype better over a period of time using several observations. Such a strategy could limit regression dilution bias, if the examinations are repeated over a short period of time. In our study, however, these examinations spanned a time period of twenty years, and the examinations used different echocardiographic equipment that may introduce misclassification. Further, such averaging assumes that similar sets of genes and environmental factors influence traits over a wide age range. Such an assumption may not be true, i.e., agedependent gene effects may be masked by averaging of observations across ages in participants. Lastly, our sample was white and of European descent. The generalizability of our findings to other ethnicities is unknown. 


\section{Conclusion}

In hypothesis-generating GWAS of Echo, ETT response and BA vascular function in a moderate size communitybased sample, we identified several SNPs that are potential candidates for replication. Overall, our investigation provides a scientific framework for analyzing and interpreting GWAS of phenotypes fundamental to our understanding of cardiac and vascular remodeling and hemodynamic responses to exercise testing. We expect the Framingham 100K SNP data to serve as a valuable scientific resource by virtue of the web-posting of unfiltered aggregate data

\section{Abbreviations}

$\mathrm{BA}=$ brachial artery. $\mathrm{CVD}=$ cardiovascular disease. $\mathrm{ETT}=$ exercise treadmill test. FBAT = family-based association test. FHS = Framingham Heart Study. FMD = flow-mediated dilation. GEE = generalized estimating equations. GWAS = genome-wide association. IVS = interventricular septum. $\mathrm{LA}=$ left atrium. $\mathrm{LOD}=$ logarithm of odds. $\mathrm{LV}=$ left ventricular. $\mathrm{LVM}=\mathrm{LV}$ mass. $\mathrm{LVWT}=\mathrm{LV}$ wall thickness. LVDD = LV diastolic diameter. LVSD = LV systolic diameter. $\mathrm{PW}=$ posterior wall. $\mathrm{SNP}=$ single nucleotide polymorphism.

\section{Competing interests}

None of the authors have a competing interest relevant to the subject of this manuscript. GFM is the owner of Cardiovascular Engineering, Inc, a company that designs and manufactures devices that measure vascular stiffness. The company uses these devices in clinical trials that evaluate the effects of diseases and interventions on vascular stiffness.

\section{Authors' contributions}

RSV conceived the study design, planned the analyses, drafted and critically revised the manuscript. MGL planned the study, assisted in securing funding for BA function, planned and conducted the analyses, and critically revised the manuscript. JA critically revised the manuscript. TJW contributed to the analysis and interpretation of data, revising of the manuscript for important intellectual content. GFM assisted in obtaining funding for BA function measures, contributed to data acquisition, and critically revised the manuscript. SK and CNC participated in the study design, interpretation of data, and reviewed the manuscript. JAV assisted in securing funding for BA function measures and revising the manuscript. MJK contributed to collecting the BA function data base and reviewing the manuscript. COD and DL participated in the study conception and design, interpretation of data and reviewed the manuscript. EJB provided critical input designing the study, securing funding for BA function and echo measures, acquiring measurements, planning the analyses and critically revising the manuscript.

\section{Acknowledgements}

This work was supported by the National Heart, Lung and Blood Institute's Framingham Heart Study (contract No. NOI-HC-25195), the Boston University Linux Cluster for Genetic Analysis (LinGA) funded by the NIH NCRR (National Center for Research Resources) Shared Instrumentation grant ISIORR I 63736-0IAI, and NIH grants K23-HL-074077 (TJW), K23HL080025 (Dr. Newton-Cheh), 6R0I-NS I7950; IROI HL60040 (EJB); ROI HL70I00 (EJB), HL080I 24 (RSV) and K24-HL04334 (RSV).

This article has been published as part of BMC Medical Genetics Volume 8 Supplement 1, 2007: The Framingham Heart Study 100,000 single nucleotide polymorphisms resource. The full contents of the supplement are available online at http://www.biomedcentral.com/|47|-2350/8? issue=SI.

\section{References}

I. Thom T, Haase N, Rosamond W, Howard VJ, Rumsfeld J, Manolio T, Zheng ZJ, Flegal K, O'Donnell C, Kittner S, Lloyd-Jones D, Goff DC Jr, Hong $Y$, Members of the Statistics Committee and Stroke Statistics Subcommittee, Adams R, Friday G, Furie K, Gorelick P, Kissela B, Marler J, Meigs J, Roger V, Sidney S, Sorlie P, Steinberger J, et al.: Heart Disease and Stroke Statistics - 2006 Update: A Report From the American Heart Association Statistics Committee and Stroke Statistics Subcommittee. Circulation 2006, I | 3:e85-|5|.

2. Ben-Shlomo $Y$, Kuh D: A life course approach to chronic disease epidemiology: conceptual models, empirical challenges and interdisciplinary perspectives. Int J Epidemiol 2002, 3 I:285-293.

3. Kuller LH, Shemanski L, Psaty BM, Borhani NO, Gardin J, Haan MN, O'Leary DH, Savage PJ, Tell GS, Tracy R: Subclinical Disease as an Independent Risk Factor for Cardiovascular Disease. Circulation 1995, 92:720-726.

4. Iso H, Kiyama M, Doi M, Nakanishi N, Kitamura A, Naito Y, Sato S, lida $M$, Konishi $M$, Shimamoto $T$ : Left ventricular mass and subsequent blood pressure changes among middle-aged men in rural and urban Japanese populations. Circulation 1994, 89: $1717-1724$.

5. Post WS, Larson MG, Levy D: Impact of left ventricular structure on the incidence of hypertension. The Framingham Heart Study. Circulation 1994, 90:179-185.

6. Levy D, Garrison RJ, Savage DD, Kannel WB, Castelli WP: Prognostic implications of echocardiographically determined left ventricular mass in the Framingham Heart Study. NEW ENGL J MED 1990, 322:1561-1566.

7. Vasan RS, Larson MG, Levy D, Evans JC, Benjamin EJ: Distribution and categorization of echocardiographic measurements in relation to reference limits: the Framingham Heart Study: formulation of a height- and sex-specific classification and its prospective validation. Circulation 1997, 96: I863-1873.

8. Bikkina M, Levy D, Evans JC, Larson MG, Benjamin EJ, Wolf PA, Castelli WP: Left ventricular mass and risk of stroke in an elderly cohort. The Framingham Heart Study. JAMA 1994, 272:33-36.

9. Gardin JM, McClelland R, Kitzman D, Lima JA, Bommer W, Klopfenstein HS, Wong ND, Smith VE, Gottdiener J: M-mode echocardiographic predictors of six- to seven-year incidence of coronary heart disease, stroke, congestive heart failure, and mortality in an elderly cohort (the Cardiovascular Health Study). Am J Cardiol 200I, 87:105I-1057.

10. Gottdiener JS, Arnold AM, Aurigemma GP, Polak JF, Tracy RP, Kitzman DW, Gardin JM, Rutledge JE, Boineau RC: Predictors of congestive heart failure in the elderly: the Cardiovascular Health Study. J AM COLL CARDIOL 2000, 35: I628-I637.

I I. Gottdiener JS, McClelland RL, Marshall R, Shemanski L, Furberg CD, Kitzman DW, Cushman M, Polak J, Gardin JM, Gersh BJ, Aurigemma GP, Manolio TA: Outcome of congestive heart failure in elderly persons: influence of left ventricular systolic function. The Cardiovascular Health Study. Ann Intern Med 2002, 137:631-639.

12. Vasan RS, Larson MG, Benjamin EJ, Evans JC, Levy D: Left ventricular dilatation and the risk of congestive heart failure in people without myocardial infarction. $N$ Engl J Med 1997, 336: 1350-1355 
13. Gibbons RJ, Balady GJ, Timothy Bricker J, Chaitman BR, Fletcher GF, Froelicher VF, Mark DB, McCallister BD, Mooss AN, O'Reilly MG, Winters WL Jr, Gibbons RJ, Antman EM, Alpert JS, Faxon DP, Fuster V, Gregoratos G, Hiratzka LF, Jacobs AK, Russell RO, Smith SC Jr, Committee M, Task FM: ACC/AHA 2002 Guideline Update for Exercise Testing: Summary Article: A Report of the American College of Cardiology/American Heart Association Task Force on Practice Guidelines (Committee to Update the 1997 Exercise Testing Guidelines). Circulation 2002, 106: |883-1892.

14. Benjamin EJ, Larson MG, Keyes MJ, Mitchell GF, Vasan RS, Keaney JF Jr, Lehman BT, Fan S, Osypiuk E, Vita JA: Clinical correlates and heritability of flow-mediated dilation in the community: the Framingham Heart Study. Circulation 2004, 109:613-619.

15. Brevetti G, Silvestro A, Schiano V, Chiariello M: Endothelial dysfunction and cardiovascular risk prediction in peripheral arterial disease: additive value of flow-mediated dilation to ankle-brachial pressure index. Circulation 2003, I 08:2093-2098.

16. Kuvin JT, Patel AR, Sliney KA, Pandian NG, Rand WM, Udelson JE, Karas RH: Peripheral vascular endothelial function testing as a noninvasive indicator of coronary artery disease. J Am Coll Cardiol 200I, 38:1843-1849.

17. Arnett DK, Hong Y, Bella JN, Oberman A, Kitzman DW, Hopkins PN, Rao DC, Devereux RB: Sibling correlation of left ventricular mass and geometry in hypertensive African Americans and whites: the HyperGEN study. Hypertension Genetic Epidemiology Network. Am J Hypertens 200I, I4:I226-I230.

18. Bella JN, MacCluer JW, Roman MJ, Almasy L, North KE, Best LG, Lee ET, Fabsitz RR, Howard BV, Devereux RB: Heritability of left ventricular dimensions and mass in American Indians: The Strong Heart Study. J Hypertens 2004, 22:28I-286.

19. Bielen E, Fagard R, Amery A: The inheritance of left ventricular structure and function assessed by imaging and Doppler echocardiography. Am Heart J 199|, I 2 I: I743- I 749.

20. Chien KL, Hsu HC, Su TC, Chen MF, Lee YT: Heritability and major gene effects on left ventricular mass in the Chinese population: a family study. BMC Cardiovasc Disord 2006, 6:37.

21. Harshfield GA, Grim CE, Hwang C, Savage DD, Anderson SJ: Genetic and environmental influences on echocardiographically determined left ventricular mass in black twins. Am Hypertens 1990, 3:538-543.

22. Palatini P, Krause L, Amerena J, Nesbitt S, Majahalme S, Tikhonoff V Valentini M, Julius S: Genetic contribution to the variance in left ventricular mass: the Tecumseh Offspring Study. J Hypertens 2001, 19:1217-1222

23. Palatini P, Amerena J, Nesbitt S, Valentini M, Majahalme S, Krause L, Tikhonoff $V$, Julius S: Heritability of left atrial size in the Tecumseh population. Eur J Clin Invest 2002, 32:467-47I.

24. Post WS, Larson MG, Myers RH, Galderisi M, Levy D: Heritability of Left Ventricular Mass : The Framingham Heart Study. Hypertension 1997, 30:1025-1028.

25. Rankinen T, Bouchard C: Genetics and blood pressure response to exercise, and its interactions with adiposity. Prev Cardiol 2002, 5: $138-144$.

26. Schunkert H, Brockel U, Hengstenberg C, Luchner A, Muscholl MW, Kurzidim K, Kuch B, Doring A, Riegger GA, Hense HW: Familial predisposition of left ventricular hypertrophy. J Am Coll Cardiol 1999, 33:1685-1691.

27. Swan L, Birnie DH, Padmanabhan S, Inglis G, Connell JMC, Hillis WS: The genetic determination of left ventricular mass in healthy adults. Eur Heart J 2003, 24:577-582.

28. Bella JN, MacCluer JW, Roman MJ, Almasy L, North KE, Welty TK, Lee ET, Fabsitz RR, Howard BV, Devereux RB: Genetic influences on aortic root size in American Indians: the Strong Heart Study. Arterioscler Thromb Vasc Biol 2002, 22: I008-I0I I.

29. Arnett DK, Devereux RB, Kitzman D, Oberman A, Hopkins P, Atwood L, Dewan A, Rao DC: Linkage of left ventricular contractility to chromosome I I in humans: The HyperGEN Study. Hypertension 200I, 38:767-772.

30. Arnett DK, de las FL, Broeckel U: Genes for left ventricular hypertrophy. Curr Hypertens Rep 2004, 6:36-4I.

31. Rankinen T, An P, Rice T, Sun G, Chagnon YC, Gagnon J, Leon AS, Skinner JS, Wilmore JH, Rao DC, Bouchard C: Genomic scan for exercise blood pressure in the Health, Risk Factors, Exercise Training and Genetics (HERITAGE) Family Study. Hypertension 200I, 38:30-37.
32. Hirschhorn JN, Daly MJ: Genome-wide association studies for common diseases and complex traits. Nat Rev Genet 2005, 6:95-108.

33. Klein RJ, Zeiss C, Chew EY, Tsai JY, Sackler RS, Haynes C, Henning AK, SanGiovanni JP, Mane SM, Mayne ST, Bracken MB, Ferris FL, Ott J, Barnstable $\mathrm{C}$, Hoh J: Complement factor $\mathbf{H}$ polymorphism in age-related macular degeneration. Science 2005, 308:385-389.

34. Herbert A, Gerry NP, McQueen MB, Heid IM, Pfeufer A, Illig T, Wichmann HE, Meitinger T, Hunter D, Hu FB, Colditz G, Hinney A, Hebebrand J, Koberwitz K, Zhu X, Cooper R, Ardlie K, Lyon H, Hirschhorn JN, Laird NM, Lenburg ME, Lange C, Christman MF: A Common Genetic Variant Is Associated with Adult and Childhood Obesity. Science 2006, 3 I 2:279-283.

35. Dawber TR, Meadors GF, Moore FE: Epidemiologic approaches to heart disease: the Framingham Study. Am J Public Health | 95 I, 4 | :279-286.

36. Kannel WB, Feinleib M, McNamara PM, Garrison RJ, Castelli WP: An investigation of coronary heart disease in families. The Framingham offspring study. Am J Epidemiol 1979, I | 0:28 I-290.

37. Cupples LA, Aruda H, Benjamin EJ, D'Agostino RB Sr, Demissie S, DeStefano AL, Dupuis J, Falls K, Fox CS, Gottlieb DJ, Govindaraju DR, Guo CY, Heard-Costa N, Hwang SJ, Kathiresan S, Kiel DP, Laramie JM, Larson MG, Levy D, Liu CY, Lunetta KL, Mailman MD, Manning AK, Meigs JB, Murabito JM, Newton-Cheh C, O'Connor GT, O'Donnell CJ, Pandey MA, Seshadri S, Vasan RS, Wang ZY, Wilk JB, Wolf PA, Yang Q, Atwood LD: The Framingham Heart Study I00K SNP genome-wide association study resource: Overview of I 7 phenotype working group reports. BMC Med Genet 2007, 8(Suppl I):SI.

38. Sahn DJ, DeMaria A, Kisslo J, Weyman A: Recommendations regarding quantitation in $M$-mode echocardiography: results of a survey of echocardiographic measurements. Circulation 1978, 58: 1072-1083.

39. Devereux RB, Alonso DR, Lutas EM, Gottlieb G], Campo E, Sachs I, Reichek N: Echocardiographic assessment of left ventricular hypertrophy: comparison to necropsy findings. Am J Cardio 1986, 57:450-458.

40. Sundstrom J, Sullivan L, Selhub J, Benjamin EJ, D'Agostino RB, Jacques PF, Rosenberg IH, Levy D, Wilson PWF, Vasan RS: Relations of plasma homocysteine to left ventricular structure and function: the Framingham Heart Study. Eur Heart J 2004, 25:523-530.

41. Mitchell GF, Parise H, Vita JA, Larson MG, Warner E, Keaney JF Jr, Keyes MJ, Levy D, Vasan RS, Benjamin EJ: Local Shear Stress and Brachial Artery Flow-Mediated Dilation: The Framingham Heart Study. Hypertension 2004, 44: I34- I39.

42. Blanchard BE, Tsongalis GJ, Guidry MA, LaBelle LA, Poulin M, Taylor AL, Maresh CM, Devaney J, Thompson PD, Pescatello LS: RAAS polymorphisms alter the acute blood pressure response to aerobic exercise among men with hypertension. Eur J Appl Physiol 2006, 97:26-33.

43. Celentano A, Mancini FP, Crivaro M, Palmieri V, Ferrara LA, De SV, Di MG, de SG: Cardiovascular risk factors, angiotensin-converting enzyme gene I/D polymorphism, and left ventricular mass in systemic hypertension. Am J Cardiol I999, 83: I I 96- I 200.

44. Defoor J, Martens K, Zielinska D, Matthijs G, Van NH, Schepers D, Fagard R, Vanhees L: The CAREGENE study: polymorphisms of the beta I-adrenoceptor gene and aerobic power in coronary artery disease. Eur Heart J 2006, 27:808-8I6.

45. Hautala AJ, Rankinen T, Kiviniemi AM, Makikallio TH, Huikuri HV, Bouchard $C$, Tulppo MP: Heart rate recovery after maximal exercise is associated with acetylcholine receptor $\mathrm{M} 2$ (CHRM2) gene polymorphism. Am J Physiol Heart Circ Physio 2006, 29l:H459-H466.

46. Kathiresan S, Larson MG, Vasan RS, Guo CY, Vita JA, Mitchell GF, Keyes MJ, Newton-Cheh C, Musone SL, Lochner AL, Drake JA, Levy D, O'Donnell C], Hirschhorn JN, Benjamin EJ: Common genetic variation at the endothelial nitric oxide synthase locus and relations to brachial artery vasodilator function in the community. Circulation 2005, I I 2: |4|9-| 427

47. Kurland L, Melhus H, Sarabi M, Millgard J, Ljunghall S, Lind L: Polymorphisms in the renin-angiotensin system and endothelium-dependent vasodilation in normotensive subjects. Clin Physiol 2001, 2 I:343-349.

48. Kuznetsova T, Staessen JA, Thijs L, Kunath C, Olszanecka A, Ryabikov A, Tikhonoff V, Stolarz K, Bianchi G, Casiglia E, Fagard R, Brand-Her- 
rmann SM, Kawecka-Jaszcz K, Malyutina S, Nikitin Y, Brand E, for the European Project On Genes in Hypertension Investigators: Left Ventricular Mass in Relation to Genetic Variation in Angiotensin II Receptors, Renin System Genes, and Sodium Excretion. Circulation 2004, I 1 0:2644-2650.

49. Roltsch MH, Brown MD, Hand BD, Kostek MC, Phares DA, Huberty A, Douglass LW, Ferrell RE, Hagberg JM: No association between ACE I/D polymorphism and cardiovascular hemodynamics during exercise in young women. Int J Sports Med 2005, 26:638-644.

50. Tambur AR, Pamboukian S, Costanzo MR, Heroux A: Genetic polymorphism in platelet-derived growth factor and vascular endothelial growth factor are significantly associated with cardiac allograft vasculopathy. J Heart Lung Transplant 2006, 25:690-698.

51. Tang W, Devereux RB, Rao DC, Oberman A, Hopkins PN, Kitzman DW, Arnett DK: Associations between angiotensinogen gene variants and left ventricular mass and function in the HyperGEN study. Am Heart J 2002, I 43:854-860.

52. An P, Perusse L, Rankinen T, Borecki IB, Gagnon J, Leon AS, Skinner $\mathrm{JS}$, Wilmore $\mathrm{JH}$, Bouchard C, Rao DC: Familial aggregation of exercise heart rate and blood pressure in response to 20 weeks of endurance training: the HERITAGE family study. Int J Sports Med 2003, 24:57-62.

53. Itoh A, Miyabayashi T, Ohno M, Sakano S: Cloning and expressions of three mammalian homologues of Drosophila slit suggest possible roles for Slit in the formation and maintenance of the nervous system. Brain Res Mol Brain Res 1998, 62:175-186.

54. Liu D, Hou J, Hu X, Wang X, Xiao Y, Mou Y, De LH: Neuronal chemorepellent Slit2 inhibits vascular smooth muscle cell migration by suppressing small GTPase Racl activation. Circ Res 2006, 98:480-489.

55. Iwabuchi K, Tajima M, Isoyama S: Heat shock protein expression in hearts hypertrophied by genetic and nongenetic hypertension. Heart Vessels 1998, 13:30-39.

56. Haugen E, Chen J, Wikstrom J, Gronros J, Gan LM, Fu LX: Parallel gene expressions of IL-6 and BNP during cardiac hypertrophy complicated with diastolic dysfunction in spontaneously hypertensive rats. Int J Cardiol 2006.

57. Benkusky NA, Farrell EF, Valdivia HH: Ryanodine receptor channelopathies. Biochem Biophys Res Commun 2004, 322: I 280-I 285.

58. Priori SG, Napolitano C, Tiso N, Memmi M, Vignati G, Bloise R, Sorrentino V, Danieli GA: Mutations in the Cardiac Ryanodine Receptor Gene (hRyR2) Underlie Catecholaminergic Polymorphic Ventricular Tachycardia. Circulation 200I, 103: 196-200.

59. Lang T, Yu L, Tu Q, Jiang J, Chen Z, Xin Y, Liu G, Zhao S: Molecular cloning, genomic organization, and mapping of PRKAG2, a heart abundant gamma2 subunit of 5'-AMP-activated protein kinase, to human chromosome 7q36. Genomics 2000, 70:258-263.

60. Gollob MH, Green MS, Tang AS, Gollob T, Karibe A, li Hassan AS, Ahmad F, Lozado R, Shah G, Fananapazir L, Bachinski LL, Roberts R: Identification of a gene responsible for familial Wolff-Parkinson-White syndrome. $N$ Engl J Med 200I, 344:I823-I83I.

61. Lin Q, Schwarz J, Bucana C, Olson EN: Control of mouse cardiac morphogenesis and myogenesis by transcription factor MEF2C. Science 1997, 276: I 404-| 407.

62. Xu J, Gong NL, Bodi I, Aronow BJ, Backx PH, Molkentin JD: Myocyte enhancer factors $2 \mathrm{~A}$ and $2 \mathrm{C}$ induce dilated cardiomyopathy in transgenic mice. J Biol Chem 2006, 281:9152-9162.

63. Williamson D, Gallagher P, Harber M, Hollon C, Trappe S: Mitogenactivated protein kinase (MAPK) pathway activation: effects of age and acute exercise on human skeletal muscle. J Physiol 2003, 547:977-987.

64. Nakano N, Higashiyama $\mathrm{S}$, Ohmoto $\mathrm{H}$, Ishiguro $\mathrm{H}$, Taniguchi $\mathrm{N}$, Wada Y: The $\mathbf{N}$-terminal region of NTAK/neuregulin-2 isoforms has an inhibitory activity on angiogenesis. J Biol Chem 2004, 279: I I465-II470.

65. Robert R, Norez C, Becq F: Disruption of CFTR chloride channel alters mechanical properties and cAMP-dependent $\mathrm{Cl}$ transport of mouse aortic smooth muscle cells. J Physiol (Lond) 2005, 568:483-495.

66. Tousson A, Van Tine BA, Naren AP, Shaw GM, Schwiebert LM: Characterization of CFTR expression and chloride channel activity in human endothelia. Am J Physiol Cell Physiol 1998, 275:CI555-CI564

67. Lin CS, Lin G, Xin ZC, Lue TF: Expression, distribution and regulation of phosphodiesterase 5. Curr Pharm Des 2006, I 2:3439-3457.

68. Kim D, Aizawa T, Wei H, Pi X, Rybalkin SD, Berk BC, Yan C: Angiotensin II increases phosphodiesterase 5A expression in vascular smooth muscle cells: a mechanism by which angiotensin II antagonizes cGMP signaling. J Mol Cell Cardiol 2005, 38: $175-184$.

69. Kardia SL: Context-dependent genetic effects in hypertension. Curr Hypertens Rep 2000, 2:32-38.
Publish with Bio Med Central and every scientist can read your work free of charge

"BioMed Central will be the most significant development for disseminating the results of biomedical research in our lifetime. "

Sir Paul Nurse, Cancer Research UK

Your research papers will be:

- available free of charge to the entire biomedical community

- peer reviewed and published immediately upon acceptance

- cited in PubMed and archived on PubMed Central

- yours - you keep the copyright

Submit your manuscript here:

http://www.biomedcentral.com/info/publishing_adv.asp
BioMedcentral 